\title{
BMJ Open A population-based case-control study of hospitalisation due to head injuries among bicyclists and motorcyclists in Taiwan
}

\author{
Chih-Wei Pai, ${ }^{1}$ Yi-Chu Chen, ${ }^{2}$ Hsiao-Yu Lin, ${ }^{3}$ Ping-Ling Chen ${ }^{1}$
}

To cite: Pai C-W, Chen Y-C, Lin H-Y, et al. A populationbased case-control study of hospitalisation due to head injuries among bicyclists and motorcyclists in Taiwan. BMJ Open 2017;7:e018574. doi:10.1136/ bmjopen-2017-018574

- Prepublication history and additional material for this paper are available online. To view these files, please visit the journal online (http://dx.doi. org/10.1136/bmjopen-2017018574).

$\mathrm{H}-\mathrm{YL}$ and P-LC contributed equally.

Received 7 July 2017 Revised 11 October 2017 Accepted 13 October 2017

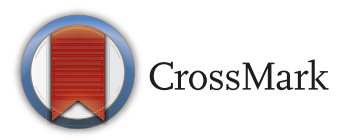

${ }^{1}$ Graduate Institute of Injury Prevention and Control, College of Public Health, Taipei Medical University, Taipei, Taiwan ${ }^{2}$ Graduate Institute of Public Health, College of Public Health, Taipei Medical University, Taipei, Taiwan

${ }^{3}$ Department of Urology, Taipei Medical University Hospital,

Taipei, Taiwan

Correspondence to

Dr Hsiao-Yu Lin;

ablin@tmu.edu.tw and Professor Ping-Ling Chen; plchen@tmu. edu.tw

\section{ABSTRACT}

Introduction According to official statistics in Taiwan, the main body region of injury causing bicyclist deaths is the head, and bicyclists are 2.6 times more likely to be fatally injured than motorcyclists. There is currently a national helmet law for motorcyclists but not for bicyclists. Objectives The primary aim of this study was to determine whether bicyclist casualties have higher odds of head-related hospitalisation than motorcyclists. This study also aims to investigate the determinants of head injuryrelated hospitalisation among bicyclists and motorcyclists. Methods Using linked data from the National Traffic Accident Dataset and the National Health Insurance Research Database for the period 2003-2012, this study investigates the crash characteristics of bicyclist and motorcyclist casualties presenting to hospitals due to motor vehicle crashes. Head injury-related hospitalisation was used as the study outcome for both road users to evaluate whether various factors (eg, human attributes, road and weather conditions, vehicle characteristics) are related to hospital admission of those who sustained serious injuries.

Results Among 1239474 bicyclist and motorcyclist casualties, the proportion of bicyclists hospitalised for head injuries was higher than that of motorcyclists $(10.0 \%$ vs $6.5 \%)$. However, the multiple logistic regression model shows that, after adjustment of this result for other factors such as helmet use, bicyclists were $18 \%$ significantly less likely to be hospitalised for head injuries than motorcyclists (AOR 0.82, 95\% Cl 0.79 to 0.85). Other important determinants of head injury-related hospitalisation for bicyclists and motorcyclists include female riders, elderly riders, crashes occurring in rural areas, moped riders, riding unhelmeted, intoxicated bicyclists and motorcyclists, unlicensed motorcyclists, dusk and dawn conditions and single-vehicle crashes.

Conclusions Our finding underscores the importance of helmet use in reducing hospitalisation due to head injuries among bicyclists while current helmet use is relatively low.

\section{INTRODUCTION}

Two-wheeled motor vehicle crashes involving bicyclists and motorcyclists have been a serious safety problem in Taiwan with regard to injury severity and frequency. Studies have suggested that head injuries are the
Strengths and limitations of this study

- This is a comprehensive study using linked data from two datasets which cover $99.9 \%$ of the population.

- Our results derived from the linked datasets are more reliable than those using a single database.

- Hospitalisation data are more clinically reliable than injury severity data, which have commonly been used in past studies.

- The study is limited by data that are unavailable from the two datasets such as electronic device use (eg, phone and MP3 players).

primary cause of deaths and hospitalisation among bicyclists and motorcyclists. ${ }^{1-3} \mathrm{~A}$ study reported that, in Taiwan, bicyclists are 2.6 times more likely to be fatally injured than motorcyclists. ${ }^{4}$ The main body part that sustained injury resulting in death of these bicyclists was the head (approximately $61 \%$ ). ${ }^{5}$ Head injuries among motorcyclists have become less problematic since the enforcement of the helmet use law for motorcyclists in $1997 .^{6}$ Chiu et al investigated motorcycle head injuries 1 year after the enforcement of the helmet use law in Taiwan and reported a $33 \%$ reduction in head injuries. ${ }^{6}$ Helmet use became mandatory for users of electric bicycles in 2016, but not for conventional bicycles.

According to official accident statistics (National Traffic Accident Dataset), the number of motorcycle accidents has been steadily decreasing; however, the number of bicycle accidents has been stably increasing. This is primarily attributable to the increasing popularity of bicycle use. For instance, several bicycle sharing programmes have been implemented in a number of metropolitan cities such as Taipei City and Taichuang City. In addition, the use of electric bicycles and racing bikes, which are widely used for recreational purposes and travelling between cities, has been increasing. 
Studies conducted mainly in Asian countries on helmet use and motorcyclist injuries have reported that helmet use and related laws have successfully reduced head injuries, thus reducing fatalities among motorcyclists. Ichiwaka $e t$ al reported a $41 \%$ reduction in head injuries in Thailand 2 years after the implementation of a mandatory helmet use law. ${ }^{7}$ A similar reduction in head injuries and fatalities has been reported in Malaysia, ${ }^{8}$ Vietnam, ${ }^{9}$ USA $^{3}$ and Italy ${ }^{10}$ after the implementation of helmet use laws. Bicycle helmet use is a means of reducing morbidity and mortality among bike users. Several case-controlled studies have reported an association between helmet use and a decreased rate of head injury and mortality among riders of all ages, with bicycle helmets reducing the risk of head and brain injury by $65-88 \% .{ }^{11}$ Moreover, Attewell $e t$ $a l^{12}$ conducted a meta-analysis of 16 observational studies and reported that bicycle helmets can significantly reduce the risks of head injury by approximately $60 \%$.

Current efforts to increase helmet use in order to prevent head injuries in accidents include campaigns to increase awareness regarding the importance of helmet use, along with advocating helmet use laws. Over the last decades, mandatory bicycle helmet use laws have been implemented in several countries including Australia, New Zealand, Sweden and Canada. A study indicated that helmet use laws act as a deterrent to cycling. ${ }^{13}$ Other studies have similarly reported a decline in cycling due to helmet use law. ${ }^{14}$ In general, a positive effect of mandatory cycle helmet use laws on bicyclist head injuries has been observed in Australia, ${ }^{16}{ }^{17}$ Sweden $^{18}{ }^{19}$ and New Zealand. ${ }^{2021}$

Taken together, the literature suggests that helmet use and related laws are beneficial for reducing head injuries and fatalities among bicyclists and motorcyclists.

In Taiwan, helmet use is mandatory for motorcyclists but not bicyclists. This leads to an important research question of whether bicyclists involved in motor vehicle crashes (MVCs; a crash that occurs when a vehicle collides with other road users or other stationary objects such as a tree, telegraph pole or traffic island) are more likely than motorcyclists to be hospitalised due to head injuries. The primary aim of this study was to determine whether bicyclist casualties have higher odds of head-related hospitalisation than motorcyclists. Another important hypothesis of the current research is that risk factors that influence head injury-related hospitalisation among bicyclists and motorcyclists may include helmet use, alcohol consumption or license status. This study also aims to investigate the determinants of head injury-related hospitalisation among bicyclists and motorcyclists.

\section{MATERIALS AND METHODS}

\section{Data source}

Two datasets, police-reported crash data provided by the National Police Agency, Ministry of the Interior and the National Health Insurance Research Database (NHIRD) provided by the Health and Welfare Data Science Centre,
Ministry of Health and Welfare, were used in the present study. The National Traffic Accident Dataset is recorded by trained police accident investigators after an accident has been reported to police. The National Traffic Accident Dataset report forms comprise the following three files: accident, vehicle and victim files. A thorough description of the National Traffic Accident Dataset can be found in the study by Chen $e t a l .^{22}$

The Bureau of National Health Insurance (BNHI) in Taiwan implemented the National Health Insurance (NHI) programme on 1 March 1995, and the NHI covers 99\% of the residents of Taiwan. The NHIRD comprises outpatient and inpatient claims data of all NHI beneficiaries; all hospitals and clinics are required to report to the BNHI on a monthly basis. The information obtained from the NHIRD can be considered complete and accurate, ${ }^{23}$ because the BNHI ensures the accuracy of claims files by performing periodical expert reviews on a random sample for every 50-100 ambulatory and inpatient claims. The NHIRD contains data such as patients' age and gender, admission and discharge dates, care location, hospital level, treatment department, surgical procedures, medical expenditures, diagnosis of disease or injury (in accordance with International Classification of Diseases, Ninth Revision Clinical Modification (ICD-9-CM) N-codes) and cause of injury (in accordance with ICD-9-CM E-codes).

ICD-9-CM N-codes 800-999 that report injury diagnoses were used for extracting injury data. Specifically, the following N-codes were used for extracting head-related injuries: $800,801,803,804,850-854,950.1-950.3$, 995.55, 959.01, 873.0, 873.1, 870, 871, 918, 802, 872, 873.2-873.9. The encrypted personal identification data in the NHIRD were used to link externally the NHIRD dataset to the National Traffic Accident Dataset. Patients' identification information that is used for linking the two datasets is encrypted by the Health and Welfare Data Science Centre, Taiwan. No individual patient or casualty can be identified, therefore our study was exempted from review by an institutional review board (IRB \#201409033).

The flow chart of sample selection from the National Traffic Accident Dataset and the NHIRD is presented in online supplementary appendix 1 . The current research examined data for the period 2003-2012. By linking the National Traffic Accident Dataset and the NHIRD, a total of 4054668 casualties involved in MVCs were identified. Among the 4054668 casualties, 1998606 were bicyclists and motorcyclists involved in MVCs (after excluding missing data such as identification and sex data and remaining cases where victims were treated at different times). After removal of the cases where the individuals involved did not receive an injury diagnosis and where patients died within 24 hours, a total of 1239474 casualties were either hospitalised or admitted to emergency departments. Among these 1239474 casualties, 82711 were hospitalised for head injuries (treated as cases) and 1156763 were hospitalised for other injury types or received emergency treatment only (treated as controls). 


\section{Definition of variables}

The current study investigates the effects of demographic variables, temporal factors, road and environment characteristics and crash factors on head injuries among bicyclist and motorcyclist casualties. The following demographic data were collected for the casualties: gender; age $(<18$, 18-40, 41-64 and $\geq 65$ years); blood alcohol consumption (BAC) level $(\leq 0.03 \%$ or $>0.03 \%)$; license status (yes, valid license or no, without a valid license); helmet use (yes or no); and location (highly urbanised area, moderately urbanised area, boomtown, rural area). Vehicle attributes were engine size ( $\leq 50 \mathrm{cc}$ or $\geq 51 \mathrm{cc}$ ). Road and environment factors were the following: path type (straight road, curved road or crossroads/roundabout); lighting (daylight, dusk/dawn); road type (provincial highway, county road or other); road surface (dry, wet/slippery); road defect (yes or no); barrier (yes or no); traffic signal (yes or no); separation of traffic direction (yes or no); and traffic island (yes or no). Crash characteristics were the crash type (multiple-vehicle crash or single-vehicle crash) and object type (divided into fixed objects and unfixed objects).

\section{Statistical analysis}

The trend of head-related injuries among two-wheeler riders due to MVCs was compared and the difference in hospitalisation percentages was tested with the Mann-Kendall trend test. The distribution of head injury-related hospitalisation and non-head injury-related hospitalisation by a set of variables (eg, human attributes, environmental factors and vehicle characteristics) is reported. $\chi^{2}$ tests were used to compare patients hospitalised for head-related injuries with those hospitalised for other injuries. Because the dependent variable is binary (hospitalisation for head injuries vs emergency treatment or hospitalisation for other injury types), a logistic regression model was estimated to examine the determinants of hospitalisation for head injuries. A pooled logistic regression model was estimated: the first model of hospitalisation for head injuries included casualty type (bicyclists vs motorcyclists) as one of the variables. In estimating the models, variables with a significance level $(\mathrm{P}<0.2)$ in the univariate logistic regression models were then incorporated into the multivariate logistic regression models. The variance inflation factor (VIF) was used to assess multicollinearity among the variables. Only confounding variables were included in the models. Two separate models were employed to examine the determinants of hospitalisation for head injuries among bicyclists and motorcyclists. These two models determined the contributory factors which may differ between bicyclist and motorcyclist casualties.

\section{RESULTS}

The results further illustrate the trend of head injuries sustained by bicyclists and motorcyclists who presented to the emergency room or were admitted to hospital (see online supplementary appendix 2). The trend of head injuries appeared to steadily decrease among these two groups: the percentage of head injuries decreased from $16.4 \%$ and $10.2 \%$ in 2003 to $7.8 \%$ and $4.7 \%$ in 2012 among bicyclists and motorcyclists, respectively. The decreasing trend was statistically significant according to the Mann-Kendall trend test $(\mathrm{P}<0.01)$. Moreover, the risk of sustaining head injuries tended to be higher among bicyclists than among motorcyclists.

Table 1 lists the $\mathrm{N}$-codes for the principal diagnoses of injuries to various body regions resulting in hospitalisation of bicyclists and motorcyclists. Traumatic brain injury (TBI, 29.3\%), lower leg and ankle fracture $(12.3 \%$ ) and shoulder and upper arm fracture $(9.4 \%)$ were the top three injury types among motorcyclists, while TBI $(41.4 \%)$, lower leg and ankle fracture (10.7\%) and forearm and elbow fracture $(6.9 \%)$ were the top three injury types among bicyclists. The proportion of bicyclists diagnosed with TBI was higher than that of motorcyclists $(41.4 \%$ vs $29.3 \%)$.

Tables 2-4 summarise the human attributes, environmental factors and vehicle characteristics of two-wheeler casualties with head-related injuries occurring between 2003 and 2012. One of the noteworthy results is that the proportion of bicyclists hospitalised for head injuries was higher than that of motorcyclists $(10.0 \%$ vs $6.5 \%)$. The data reported in table 2 confirm that injured motorcyclists $(90.99 \%)$ had a much higher rate of helmet use than injured bicyclists and that injured bicyclists were less likely to wear a helmet $(8.70 \%)$ since there is no law requiring helmet use for bicyclists. Other noteworthy results from tables $2-4$ are not interpreted here for brevity.

Table 5 lists the crude and adjusted ORs (AORs) of hospitalisation for head injuries among bicyclists and motorcyclists using logistic regression models. Three models were estimated: a pooled model that considered the variable 'vehicle type' as a risk factor and two separate models for bicyclists and motorcyclists. According to the VIF $<3$, there was no need to be concerned about multicollinearity in the models.

The pooled model revealed that bicyclists were $18 \%$ significantly less likely to be hospitalised for head injuries than motorcyclists (AOR $0.82,95 \%$ CI 0.79 to 0.85 ). Moreover, factors such as being female (AOR 1.08, 95\% CI 1.07 to 1.10 ), age $\geq 65$ years (AOR $1.23,95 \%$ CI 1.19 to 1.28), rural areas (AOR 2.74, 95\% CI 2.66 to 2.83), BAC level $>0.03 \%$ (AOR 2.80, 95\% CI 2.73 to 2.87 ), no use of a helmet (AOR 1.77, 95\% CI 1.74 to 1.81 ), darkness (AOR $1.08,95 \%$ CI 1.03 to 1.12 ), no separator of divided traffic direction (AOR 1.21, 95\% CI 1.19 to 1.24 ) and single-vehicle crash (AOR $1.75,95 \%$ CI 1.71 to 1.79 ) were found to be most significantly associated with hospitalisation for head injuries.

The estimated crude and adjusted ORs (AORs) of the two separate models evaluating factors contributing to the hospitalisation of bicyclists and motorcyclists for head injuries were similar to those of the pooled model. Noteworthy results include that female motorcyclists 


\begin{tabular}{|c|c|c|c|c|c|c|c|c|}
\hline \multicolumn{3}{|l|}{ Total } & \multicolumn{3}{|l|}{ Motorcyclists } & \multicolumn{3}{|l|}{ Bicyclists } \\
\hline $\mathrm{N}$-code & $\mathbf{N}$ & $\%$ & $\mathrm{~N}$-code & $\mathbf{N}$ & $\%$ & $\mathrm{~N}$-code & $\mathbf{N}$ & $\%$ \\
\hline Traumatic brain injury & 67464 & 30.0 & Traumatic brain injury & 61826 & 29.3 & $\begin{array}{l}\text { Traumatic brain } \\
\text { injury }\end{array}$ & 5638 & 41.4 \\
\hline $\begin{array}{l}\text { Lower leg and ankle } \\
\text { fracture }\end{array}$ & 27358 & 12.2 & $\begin{array}{l}\text { Lower leg and ankle } \\
\text { fracture }\end{array}$ & 25908 & 12.3 & $\begin{array}{l}\text { Lower leg and ankle } \\
\text { fracture }\end{array}$ & 1450 & 10.7 \\
\hline $\begin{array}{l}\text { Shoulder and upper arm } \\
\text { fracture }\end{array}$ & 20712 & 9.2 & $\begin{array}{l}\text { Shoulder and upper } \\
\text { arm fracture }\end{array}$ & 19839 & 9.4 & $\begin{array}{l}\text { Forearm and elbow } \\
\text { fracture }\end{array}$ & 939 & 6.9 \\
\hline $\begin{array}{l}\text { Forearm and elbow } \\
\text { fracture }\end{array}$ & 16782 & 7.5 & $\begin{array}{l}\text { Forearm and elbow } \\
\text { fracture }\end{array}$ & 15843 & 7.5 & $\begin{array}{l}\text { Shoulder and upper } \\
\text { arm fracture }\end{array}$ & 873 & 6.4 \\
\hline $\begin{array}{l}\text { Other head, face and } \\
\text { neck }\end{array}$ & 15247 & 6.8 & $\begin{array}{l}\text { Other head, face, and } \\
\text { neck }\end{array}$ & 14526 & 6.9 & Hip fracture & 743 & 5.5 \\
\hline $\begin{array}{l}\text { Upper leg and thigh } \\
\text { fracture }\end{array}$ & 10975 & 4.9 & $\begin{array}{l}\text { Upper leg and thigh } \\
\text { fracture }\end{array}$ & 10528 & 5.0 & $\begin{array}{l}\text { Other head, face } \\
\text { and neck }\end{array}$ & 721 & 5.3 \\
\hline $\begin{array}{l}\text { Sternum/ribs/pelvis } \\
\text { fracture }\end{array}$ & 10888 & 4.8 & $\begin{array}{l}\text { Sternum/ribs/pelvis } \\
\text { fracture }\end{array}$ & 10509 & 5.0 & Spinal fractures & 620 & 4.6 \\
\hline $\begin{array}{l}\text { Minor injuries: } \\
\text { contusions and } \\
\text { abrasions }\end{array}$ & 8640 & 3.8 & $\begin{array}{l}\text { Minor injuries: } \\
\text { contusions and } \\
\text { abrasions }\end{array}$ & 8160 & 3.9 & $\begin{array}{l}\text { Minor injuries: } \\
\text { contusions and } \\
\text { abrasions }\end{array}$ & 480 & 3.5 \\
\hline $\begin{array}{l}\text { Minor injuries: open } \\
\text { wounds }\end{array}$ & 7807 & 3.5 & $\begin{array}{l}\text { Minor injuries: open } \\
\text { wounds }\end{array}$ & 7501 & 3.6 & $\begin{array}{l}\text { Sternum/ribs/pelvis } \\
\text { fracture }\end{array}$ & 466 & 3.4 \\
\hline $\begin{array}{l}\text { Wrist/hand/finger } \\
\text { fracture }\end{array}$ & 6411 & 2.9 & $\begin{array}{l}\text { Wrist/hand/finger } \\
\text { fracture }\end{array}$ & 6213 & 2.9 & $\begin{array}{l}\text { Upper leg and thigh } \\
\text { fracture }\end{array}$ & 360 & 2.6 \\
\hline Other injuries & 32592 & 14.5 & Other injuries & 30416 & 14.4 & Other injuries & 1317 & 9.7 \\
\hline
\end{tabular}

(AOR 1.03) and elderly bicyclists and motorcyclists (AORs 1.92 and1.23, respectively) were more likely to be hospitalised for head injuries. Accidents that occurred in rural areas were associated with a higher risk of hospitalisation for head injuries among bicyclists and motorcyclists (AORs 2.94 and 2.77, respectively). The odds of hospitalisation were higher in riders of mopeds who sustained head injuries than in heavy motorcycle riders (AOR 1.18). Intoxicated bicyclists and motorcyclists had a higher risk of hospitalisation for head injuries (AORs 2.64 and 1.48, respectively). Riding without helmets was found to be a risk factor in both bicyclists and motorcyclists (AORs 1.24 and 1.73, respectively). Motorcyclists travelling without a legal licence were more prone to be hospitalised for head injuries (AOR 1.36). Furthermore, curved roadways and dusk or dawn were associated with an increased risk of hospitalisation for head injuries among bicyclists (AORs 1.16and 1.28, respectively).

The risk of hospitalisation for head injuries was higher among bicyclists and motorcyclists involved in MVCs that occurred on roadways without separation of traffic direction (AORs 1.09 and 1.21, respectively). Moreover, the risk of hospitalisation for head injuries was $56 \%$ and $76 \%$ (AORs 1.56 and 1.76 , respectively) higher in bicyclists and motorcyclists involved in single-vehicle crashes than in those involved in multi-vehicle crashes.

\section{DISCUSSION}

To confirm the research hypotheses, the univariate results suggest that, compared with motorcyclists, bicyclists sustaining head injuries were $59 \%$ more likely to be hospitalised. However, the results of multivariate logistic models revealed that, compared with motorcyclists, bicyclists who sustained head injuries had an $18 \%$ decreased probability of being hospitalised. After the adjustment of this result for other factors, helmet use appeared to be beneficial in reducing the risks of hospitalisation for head injuries among bicyclists.

The National Traffic Accident Dataset and the NHIRD are both national datasets that cover $99.9 \%$ of the population. This is a comprehensive study using the linked data from these two datasets which facilitate the determination of various factors associated with an increased risk of hospitalisation for head injuries among bicyclists and motorcyclists in Taiwan. The conclusions drawn from the current research are therefore more reliable than other studies that solely used a single dataset.

Our finding underscores the importance of helmet use in reducing hospitalisation due to head injuries among bicyclists, in whom current helmet use is relatively low. Also, additional interventions such as education and campaigns should aim to increase riders' awareness of other factors that were found to influence head injury-related hospitalisations. Together with helmet law, these additional interventions can further reduce 


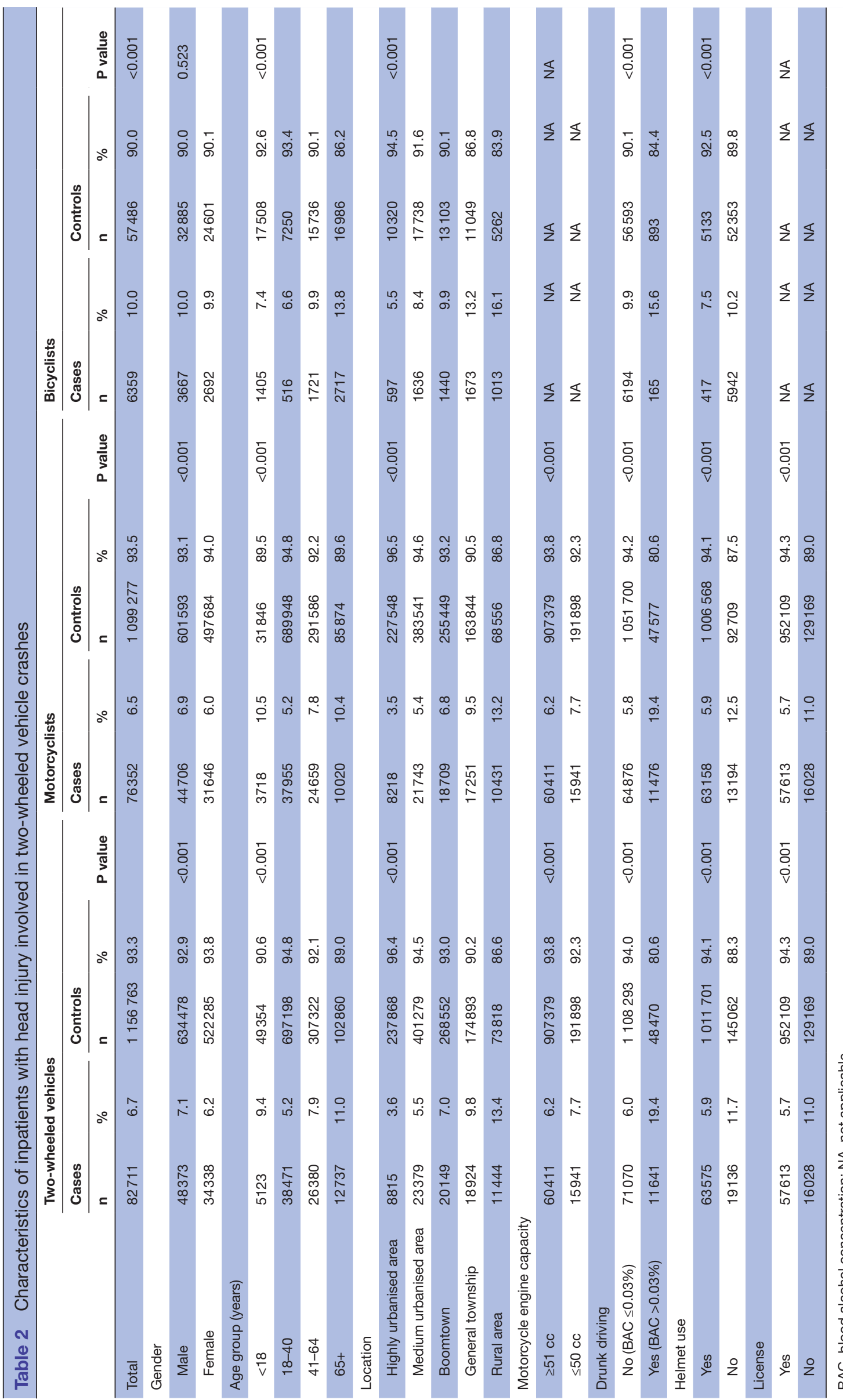




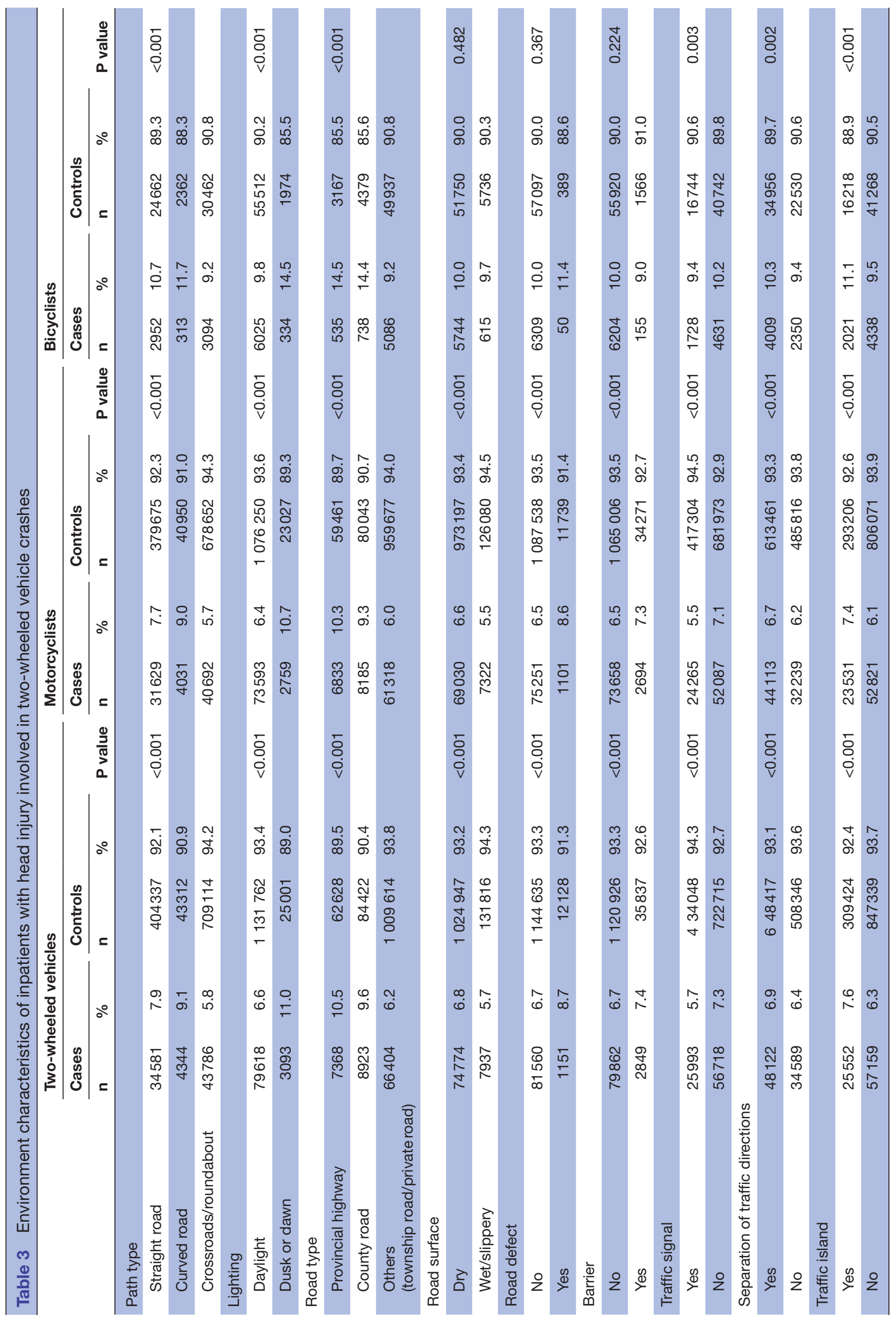

$\frac{0}{3}$
2
0
0
0
$\frac{1}{3}$

$\stackrel{\vec{B}}{\mathrm{~B}}$

음

$\frac{\bar{D}}{\bar{D}}$

क

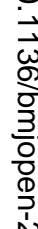

No

음

zo

$\frac{1}{3}$

옥

ํํㅇ

융

을

吾

흠.

뭉

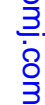

욱

을

N

స్ల

잉

$\stackrel{\circ}{\mathbb{D}}$

뭉

远

을 


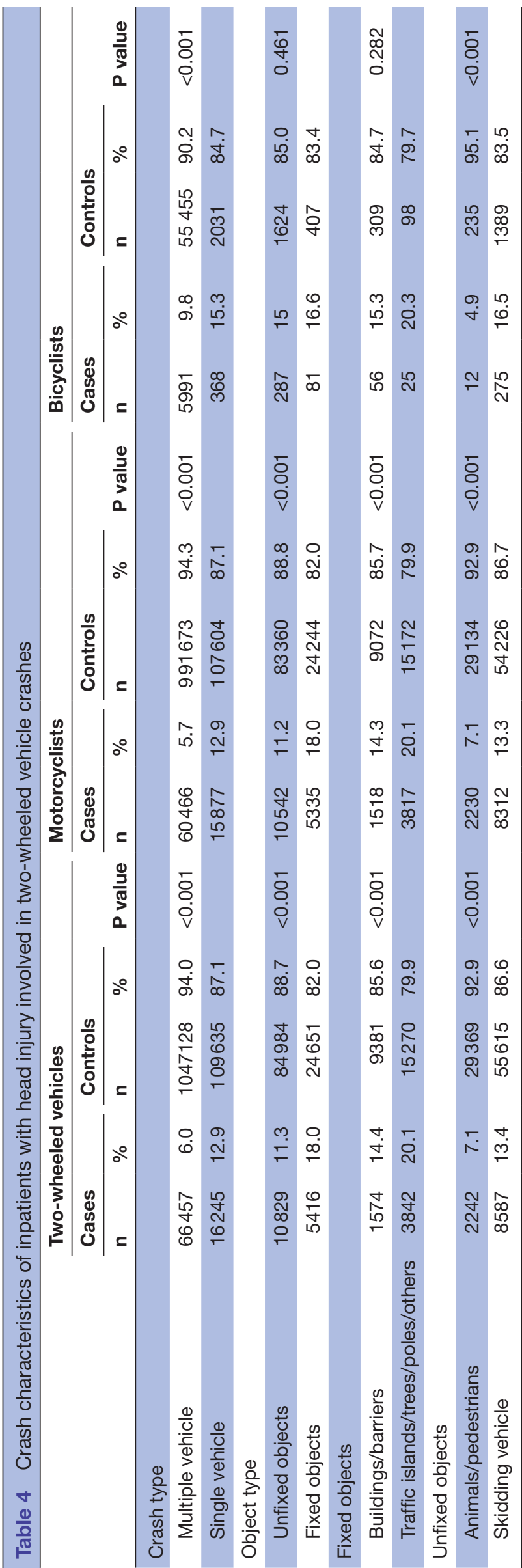

head injury-related hospitalisation for both bicyclists and motorcyclists.

The current research is limited by the fact that mortality data are not explicitly recorded in the NHIRD. Patients die even if they are hospitalised. Unfortunately no such data are available from the NHIRD; these patients are recorded as 'hospitalisations' instead of 'deaths'. Future research may attempt to obtain mortality data that are unavailable from the NHIRD, which would provide additional analysis possibilities and allow more precise model estimation.

Compared with motorcyclists, bicyclists sustaining head injuries were found to have higher risks of hospitalisation; however, after adjustment of this result for other factors in the multivariate analysis, bicyclists were found to have a lower risk of hospitalisation. These results have important implications for policymakers. In 2016, bicycle helmet use became compulsory for electric bicycle users but not for traditional bicycle users in Taiwan. A largescale nationwide travel survey ${ }^{24}$ reported that helmet use was relatively lower among bicyclists $(6.8 \%)$ than among motorcyclists $(82.2 \%)$. Because the use of electric bicycles (with higher velocities that may exacerbate crash impacts and injury outcomes) and racing bikes (which have been widely used for recreational purposes and for travelling between cities) has been increasing in recent years, the government should consider encouraging helmets for all bicycles. Further research can therefore be conducted once bicycle helmet use becomes more popular.

In this study, two additional logistic models for bicyclists and motorcyclists were estimated. The results revealed that contributory factors to hospitalisation for head injuries are similar among bicyclists and motorcyclists. For instance, dusk or dawn was associated with a higher risk of hospitalisation for head injuries among both bicyclists and motorcyclists. The findings in this study add to the existing literature on motorcycle and bicycle road safety by concluding that diminished light conditions are associated with accident occurrence ${ }^{25} 26$ and also with head injury-related hospitalisation. It seems clear that enhancing conspicuity, in particular in diminished light conditions, may be an effective countermeasure to reduce both the risk of an accident and its consequences.

Our regression models revealed that the risk of hospitalisation is higher among elderly bicyclists and motorcyclists who sustained head injuries. Such a finding is in agreement with that of Ekman $e t a l^{27}$ who reported that the risk of head injuries is higher among elderly bicyclists than their younger counterparts. This may be attributable to the fact that, compared with young people, elderly people tend to have more chronic diseases and can have more complications after head injuries, and the hospitalisation rates of elderly people can be higher after an accident. $^{28} 29$

The risk of head injury-related hospitalisation was higher among bicyclists and motorcyclists involved in single-vehicle crashes. This finding may be attributable to higher crash velocities being common in single-vehicle 


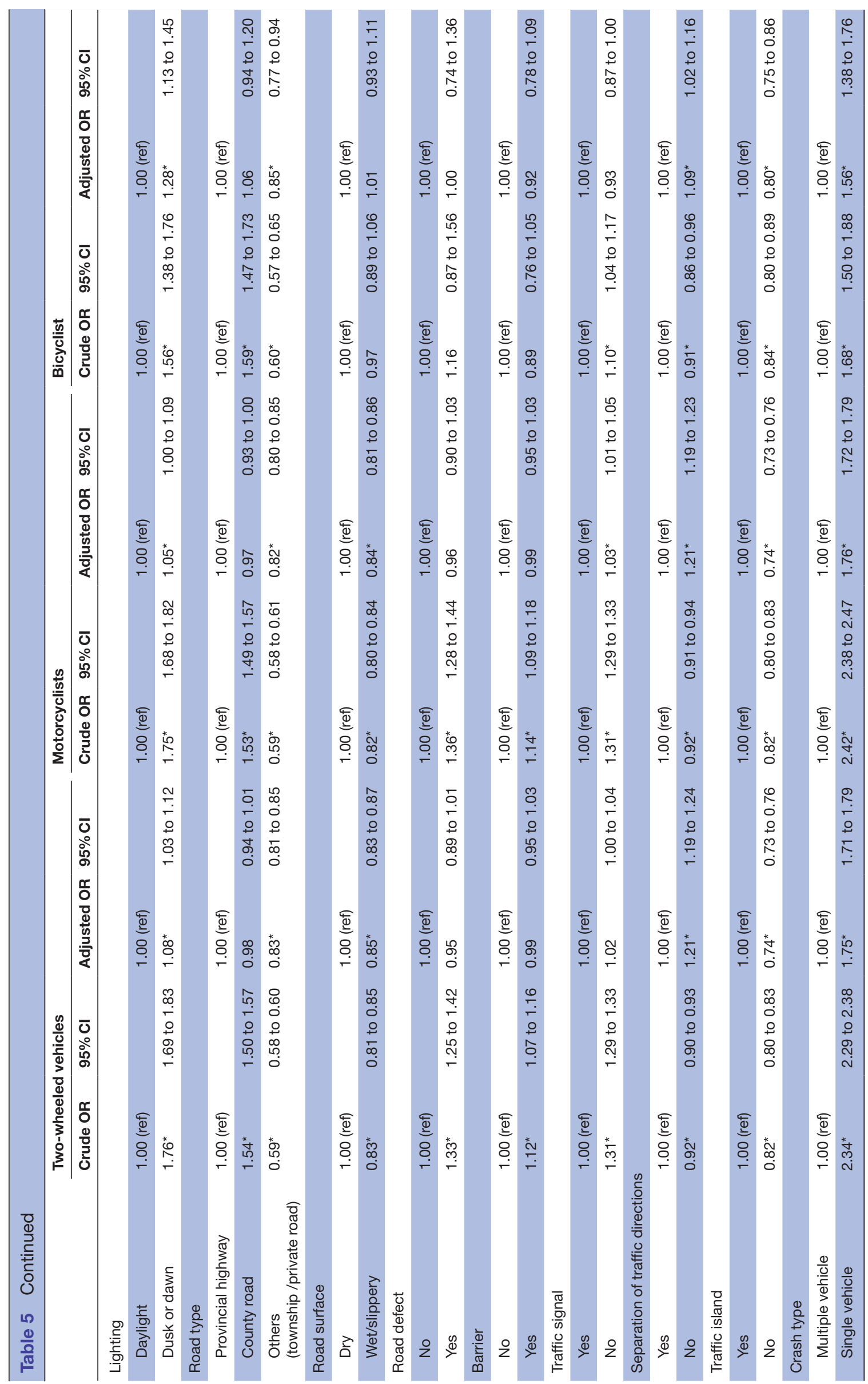


crashes, ${ }^{30}$ and helmet use being less common in rural areas where single-vehicle crashes usually occur. ${ }^{31}$ Speed management schemes that target all motorised vehicles in general and motorcycles and bicycles (eg, electric bicycles that now in general may travel at more than $25 \mathrm{~km} /$ hour ${ }^{32}$ ) in particular may constitute effective countermeasures for reducing hospitalisation rates for head injuries.

Head injury-related hospitalisation was found to be associated with accidents that occurred in rural areas. This may be because of increasing kinetic energy and greater impact at higher speeds in rural settings. ${ }^{33}{ }^{34} \mathrm{In}$ addition, heads are more likely to be exposed without any protection as a result of helmets being less commonly used in rural areas. Such a conjecture is supported by the findings of past studies ${ }^{35}$ on motorcycle helmet use which concluded that, compared with riders in cities, riders in rural areas were seven times less likely to wear a helmet. In addition, a national survey administered by the Health Promotion Administration ${ }^{24}$ reported that the bicycle helmet use rate in urbanised areas was 1.5 times higher than that in rural areas. Moreover, the requirement of additional time for emergency vehicle response in rural areas and the lower availability of medical resources in such areas $^{36}$ predispose people with head injuries to hospitalisation.

The study results showed that the risk of hospitalisation was higher in both bicyclists and motorcyclists who sustained injuries in MVCs on roadways where traffic directions were not separated. This may be because of higher crash velocities at such locations. The road sections may be wide, and speed limits may be higher for locations where the traffic is not divided by any traffic barrier. Therefore, head injuries resulting from accidents in these locations may require hospitalisation. The population-based study was conducted in Taiwan where motorcycles are the dominant transportation mode and there has been a rapid increase in cycling including bikeshare bicycles. The results derived in the current research are therefore generalisable to most other countries where there is a similar traffic composition.

Unanswered questions remain in the current research, including what other factors may affect hospitalisation due to head injuries among bicyclists and motorcyclists. Future research may attempt to obtain variables that are not available from the National Traffic Accident Dataset and the NHIRD. These factors include motorcycle and bicycle types (a greater classification of engine size and electric bicycles), traffic volume, geometric characteristics and the use of electronic devices (eg, telephones and MP3 players), which are increasingly being used when riding.

Contributors C-WP contributed to data analysis, interpretation of the data and final approval of the version to be published. Y-CC contributed to data analysis and final approval of the version to be published. H-YL contributed to the design of the work, data analysis, interpretation of the data, drafting the manuscript and final approval of the version to be published. P-LC contributed to the design of the work, data analysis, interpretation of the data, drafting the manuscript and final approval of the version to be published.
Funding This study was supported by a grant from the Health Promotion Administration, Ministry of Health and Welfare, Executive Yuan, Taiwan (Grant number: E1030909-104).

Competing interests None declared.

Ethics approval Taipei Medical University JIRB.

Provenance and peer review Not commissioned; externally peer reviewed.

Open Access This is an Open Access article distributed in accordance with the Creative Commons Attribution Non Commercial (CC BY-NC 4.0) license, which permits others to distribute, remix, adapt, build upon this work non-commercially, and license their derivative works on different terms, provided the original work is properly cited and the use is non-commercial. See: http://creativecommons.org/ licenses/by-nc/4.0/

(C) Article author(s) (or their employer(s) unless otherwise stated in the text of the article) 2017. All rights reserved. No commercial use is permitted unless otherwise expressly granted.

\section{REFERENCES}

1. Depreitere B, Van Lierde C, Maene S, et al. Bicycle-related head injury: a study of 86 cases. Accid Anal Prev 2004;36:561-7.

2. Mayrose J. The effects of a mandatory motorcycle helmet law on helmet use and injury patterns among motorcyclist fatalities. J Safety Res 2008;39:429-32.

3. Peng Y, Vaidya N, Finnie R, et al.Universal motorcycle helmet laws to reduce injuries: a community guide systematic review. Am J Prev Med 2017;52:820-32.

4. Chen PL. Statistics for injury surveillance Health Promotion Administration: Ministry of Health and Welfare, 2015.

5. Ministry of Transportation and Communications. Traffic statistics of year 2014. Republic of China, 2015.

6. Chiu WT, Chu SF, Chang CK, et al. Implementation of a motorcycle helmet law in Taiwan and traffic deaths over 18 years. JAMA 2011;306:267-8.

7. Ichikawa M, Chadbunchachai W, Marui E. Effect of the helmet act for motorcyclists in Thailand. Accid Anal Prev 2003;35:183-9.

8. Supramaniam V, van Belle G, Sung JFC. Fatal motorcycle accidents and helmet laws in Peninsular Malaysia. Accid Anal Prev 1984;16:157-62.

9. Passmore J, Tu NT, Luong MA, et al. Impact of mandatory motorcycle helmet wearing legislation on head injuries in Viet Nam: results of a preliminary analysis. Traffic Inj Prev 2010;11:202-6.

10. Servadei F, Begliomini C, Gardini E, et al. Effect of Italy's motorcycle helmet law on traumatic brain injuries. Inj Prev 2003;9:257-60.

11. Amoros E, Chiron M, Martin JL, et al. Bicycle helmet wearing and the risk of head, face, and neck injury: a French case-control study based on a road trauma registry. Inj Prev 2012;18:27-32.

12. Attewell RG, Glase K, McFadden M. Bicycle helmet efficacy: a metaanalysis. Accid Anal Prev 2001;33:345-52.

13. Clarke CF. Evaluation of New Zealand's bicycle helmet law. N Z Med J 2012;125:60-9.

14. Macpherson A, Spinks A. Bicycle helmet legislation for the uptake of helmet use and prevention of head injuries. Cochrane Database Syst Rev 2007;2:CD005401.

15. Dennis J, Potter B, Ramsay T, et al. The effects of provincial bicycle helmet legislation on helmet use and bicycle ridership in Canada. Inj Prev 2010;16:219-24.

16. Walter SR, Olivier J, Churches T, et al. The impact of compulsory cycle helmet legislation on cyclist head injuries in New South Wales, Australia. Accid Anal Prev 2011;43:2064-71.

17. Bambach MR, Mitchell RJ, Grzebieta RH, et al. The effectiveness of helmets in bicycle collisions with motor vehicles: a case-control study. Accid Anal Prev 2013;53:78-88.

18. Olofsson E, Bunketorp O, Andersson A-L. Helmet use and injuries in children's bicycle crashes in the Gothenburg region. Saf Sci 2017;92:311-7.

19. Bonander C, Nilson F, Andersson R. The effect of the Swedish bicycle helmet law for children: an interrupted time series study. $J$ Safety Res 2014;51:15-22.

20. Povey LJ, Frith WJ, Graham PG. Cycle helmet effectiveness in New Zealand. Accid Anal Prev 1999;31:763-70.

21. Scuffham P, Alsop J, Cryer C, et al. Head injuries to bicyclists and the New Zealand bicycle helmet law. Accid Anal Prev 2000;32:565-73.

22. Chen P-L, Jou R-C, Saleh W, et al. Accidents involving pedestrians with their backs to traffic or facing traffic: an evaluation of crash characteristics and injuries. J Advan Transportation 2016;50:736-51. 
23. Sun $\mathrm{Y}$, Chang $\mathrm{Y}-\mathrm{H}$, Chen $\mathrm{H}-\mathrm{F}$, et al. Risk of Parkinson disease onset in patients with diabetes. Diabetes Care 2012;35:1047-9.

24. National Health Interview Survey. Health Promotion Administration. Ministry of Health and Welfare, 2013.

25. Pai CW. Motorcycle right-of-way accidents: a literature review. Accid Anal Prev 2011;43:971-82.

26. Wood JM, Tyrrell RA, Marszalek R, et al. Bicyclists overestimate their own night-time conspicuity and underestimate the benefits of retroreflective markers on the moveable joints. Accid Anal Prev 2013;55:48-53.

27. Ekman R, Welander G, Svanström L, et al. Bicycle-related injuries among the elderly: a new epidemic? Public Health 2001;115:38-43.

28. Cook LJ, Knight S, Olson LM, et al. Motor vehicle crash characteristics and medical outcomes among older drivers in Utah, 1992-1995. Ann Emerg Med 2000;35:585-91.

29. Rakotonirainy A, Steinhardt D, Delhomme P, et al. Older drivers crashes in Queensland, Australia. Accid Anal Prev 2012;48:423-9.

30. Clabaux N, Brenac T, Perrin C, et al. Motorcyclists' speed and "looked-but-failed-to-see" accidents. Accid Anal Prev 2012;49:73-7.
31. Russo BJ, Barrette TP, Morden J, et al. Examination of factors associated with use rates after transition from a universal to partial motorcycle helmet use law. Traffic Inj Prev 2017;18:95-101.

32. Langford BC, Chen J, Cherry CR. Risky riding: naturalistic methods comparing safety behavior from conventional bicycle riders and electric bike riders. Accid Anal Prev 2015;82:220-6.

33. Pai CW, Saleh W. Exploring motorcyclist injury severity in approachturn collisions at T-junctions: focusing on the effects of driver's failure to yield and junction control measures. Accid Anal Prev 2008;40:479-86.

34. Broughton J. Car occupant and motorcyclist deaths, 1994-2002. England: Transport Research Laboratory, Crowthorne, 2005.

35. Akaateba MA, Amoh-Gyimah R, Yakubu I. A cross-sectional observational study of helmet use among motorcyclists in Wa, Ghana. Accid Anal Prev 2014;64:18-22.

36. Noland R, Quddus M. Analysis of pedestrian and bicycle casualties with regional panel data. Transp Res Rec 2004;1897:28-33. 